Tohoku J. Exp. Med., 2003, 200, 195-202

\title{
Involvement of Poly(ADP-Ribose) Synthetase in Acoustic Trauma of The Cochlea
}

Keiji Tabuchi, Tomohumi Hoshino, Hidekazu Murashita, Keiko Oikawa, Isao Uemaetomari, Bungo Nishimura, Tadamichi Tobita and Akira Hara

Department of Otolaryngology, Institute of Clinical Medicine, University of Tsukuba, Tsukuba 305-8575

Tabuchi, K., Hoshino, T., Murashita, H., Oikawa, K., Uemaetomari, I., Nishimura, B., Tobita, T. and Hara, A. Involvement of Poly(ADP-ribose) Synthetase in Acoustic Trauma of The Cochlea. Tohoku J. Exp. Med., 2003, 200 (4), 195-202 — We investigated effects of poly(ADP-ribose) synthetase (PARS) inhibitors on acoustic trauma. Albino guinea pigs were intravenously given 3 -aminobenzamide, nicotinamide or 3-aminobenzoic acid (an inactive analog of 3 -aminobenzamide) just prior to exposure to a $2 \mathrm{kHz}$ pure tone of $120 \mathrm{~dB}$ sound pressure level (SPL) for 10 minutes. The threshold of the compound action potential (CAP) and the amplitude of distortion-product otoacoustic emissions (DPOAEs) were measured before and 4 hours after the acoustic overexposure. Statistically significant decreases in the CAP threshold shifts and significant increases in the DPOAE amplitudes were observed 4 hours after the acoustic overexposure in the animals treated with 3-aminobenzamide or nicotinamide, whereas 3-aminobenzoic acid did not exert any protective effect. These results strongly suggest that excessive activation of PARS is involved in generation of the acoustic trauma. Acoustic trauma; Cochlea; Poly(ADP-ribose) synthetase (PARS)

(C) 2003 Tohoku University Medical Press

Poly(ADP-ribose) synthetase (PARS) is a nuclear enzyme that forms a polymer of ADPribose on nuclear acceptor molecules such as histones, topoisomerase and, predominantly, PARS itself. Recently, its role under pathological conditions, particularly involving the reactive oxygen species and nitric oxide (NO)induced damage, has come to interest more researchers. It has been demonstrated that reactive oxygen species (Schraufstatter et al. 1986; Hyslop et al. 1988), NO (Heller et al. 1995; Cookson et al. 1998) and peroxynitrite (Szabo et al. 1996; Cookson et al. 1998) cause DNA strand breaks, which, in turn, activate PARS to utilize nicotinamide adenine dinucleotide (NAD). Since NAD is essential to mitochondrial electron transport, NAD depletion by excessive activation of PARS interferes with production

Received June 6, 2003; revision accepted for publication August 15, 2003.

Address for reprints: Keiji Tabuchi, Department of Otolaryngology, Institute of Clinical Medicine,

University of Tsukuba, 1-1-1 Tennodai, Tsukuba 305-8575, Japan.

e-mail: ktabuchi@md.tsukuba.ac.jp 
of adenosine triphosphate (ATP) to ultimately lead to cell death (Schraufstatter et al. 1986; Hyslop et al. 1988; Heller et al. 1995; Szabo et al. 1996).

Recently, it has been demonstrated that intense sound exposure increases generation of hydroxyl radicals (Ohlemiller et al. 1999). In addition, the protective effects of free radical scavengers on acoustic trauma have been demonstrated by many researchers (Seidman et al. 1993; Yamasoba et al. 1999). These findings strongly suggest that activation of PARS by free radicals generated during and after noise exposure may also play an important role in this type of injury. However, to our knowledge, the involvement of PARS in acoustic trauma has never been examined. In order to prove the involvement of PARS, the effect of 3-aminobenzamide (3AB) and nicotinamide (NA), inhibitors of PARS, and 3-aminobenzoic acid (3ABA), an inactive analog of 3aminobenzamide (Rankin et al. 1989; Banasik et al. 1992; Thiemermann et al. 1997), on the cochlear dysfunction induced by acoustic trauma was investigated.

\section{MATERIALS AND METHODS}

\section{Animals}

Studies were performed on 46 albino guinea pigs weighing 250-350 g with a normal Preyer pinna reflex. Anesthesia was induced by pentobarbital sodium $(28 \mathrm{mg} / \mathrm{kg}$ ip., Nembutal, Abott, North Chicago, IL, USA). A supplementary dose of pentobarbital sodium was given at appropriate intervals. A cannula was inserted in the external jugular vein for administration of drugs. Body temperature was maintained at
$37 \pm 1^{\circ} \mathrm{C}$ using a heating pad. All experimental procedures used in this study were approved by the Animal Experiment Committee at University of Tsukuba under the Guidelines of the Declaration of Helsinki.

\section{Compound action potential measurement}

Methods for measuring compound action potential (CAP) were described elsewhere (Okubo et al. 1995; Tabuchi et al. 2001b). In brief, CAP was recorded at the bony edge of the round window by an $\mathrm{Ag} / \mathrm{AgCl}$ electrode. The reference electrode was placed on the neck muscles. In order to evoke CAP, tone bursts of pure tones from 2 to $16 \mathrm{kHz}$ (rise and fall times, 1 milliseconds; duration, 10 milliseconds) were delivered in an open field system. Thirty-two, 64 or 128 responses were averaged, and the sound pressure level necessary to evoke a CAP of $10 \mu \mathrm{V}$ was defined as the threshold.

Distortion-product otoacoustic emissions measurement

Because our recording methods for distortion-product otoacoustic emissions (DPOAEs) have been described elsewhere (Okubo et al. 1995; Tabuchi et al. 2001a), only a brief summary will be given here. Two primary tones were delivered to the emitters contained within a custom-made ear probe. The frequencies and levels of the primary tones are shown in Table 1. Geometric means (GM) of $\mathrm{f} 1$ and $\mathrm{f} 2$ were 4,6 and $8 \mathrm{kHz}$, and f2/f1 was fixed at 1.2, the most appropriate ratio to evoke the maximum response (Okubo et al. 1995). DPOAEs were recorded by a microphone (EK3024, Knowles, Itasca, IL, USA) inside the ear

TABle 1. Frequencies and levels of $f 1$ and $f 2$

\begin{tabular}{cccc}
\hline $\mathrm{GM}(\mathrm{Hz})$ & $\mathrm{f} 1(\mathrm{~Hz} / \mathrm{sBSPL})$ & $\mathrm{f} 2(\mathrm{~Hz} / \mathrm{dBSPL})$ & $2 \mathrm{fl}-\mathrm{f} 2(\mathrm{~Hz})$ \\
\hline 4000 & $3650 / 60$ & $4375 / 50$ & 2925 \\
6000 & $5475 / 50$ & $6575 / 40$ & 4375 \\
8000 & $7300 / 50$ & $8800 / 40$ & 5800 \\
\hline
\end{tabular}

GM, geometric means. 
probe and processed by a spectrum analyzer (CF-350, Ono Sokki, Tokyo).

\section{Experimental design}

The effects of intravenous administration of $10 \mathrm{mg} / \mathrm{kg} 3 \mathrm{AB}(n=3), 20 \mathrm{mg} / \mathrm{kg} \mathrm{NA}(n=3)$ or $10 \mathrm{mg} / \mathrm{kg} 3 \mathrm{ABA}(n=3)$ on the CAP thresholds or DPOAE amplitudes of untreated control animals were examined. The CAP thresholds or DPOAEs 4 hours after the administration were compared with the pre-administration values.

In order to induce acoustic trauma, the left ear was exposed to $2 \mathrm{kHz}$ pure tone of $120 \mathrm{~dB}$ SPL through the hollow ear bar for 10 minutes. The animals subjected to acoustic trauma were divided into the following 4 groups:

(1) 3AB-given group $(n=16)$ : Each animal in this group was intravenously given $1(n=5), 5$ $(n=5)$ or $10(n=6) \mathrm{mg} / \mathrm{kg} 3 \mathrm{AB}$ (dissolved in 3 $\mathrm{ml} / \mathrm{kg}$ physiological saline solution [PSS] ) just before the onset of acoustic exposure.

(2) NA-given group $(n=11)$ : Each animal in this group was intravenously given $10(n=5)$ or $20(n=6) \mathrm{mg} / \mathrm{kg}$ NA (dissolved in $3 \mathrm{ml} / \mathrm{kg}$ PSS) just before the onset of acoustic exposure.

(3) 3ABA-given group $(n=5)$ : Each ani- mal in this group was intravenously given 10 $\mathrm{mg} / \mathrm{kg}$ 3ABA (dissolved in $3 \mathrm{ml} / \mathrm{kg}$ PSS) just before the onset of acoustic exposure.

(4) PSS-given group $(n=5)$ : Each animal in this group received $3 \mathrm{ml} / \mathrm{kg}$ PSS intravenously just before the onset of acoustic exposure.

Shifts in the CAP thresholds and DPOAE amplitudes from the pre-exposure values were compared between the compound- and the PSSgiven groups 4 hours after the acoustic overexposure.

\section{Statistics}

All data were expressed as mean \pm S.E.M. Comparisons of CAP or DPOAEs were evaluated by two-way and one-way ANOVA followed by Scheffe test as required. A $p$-value of less than 0.05 was considered statistically significant.

\section{RESULTS}

Figs. 1A, 1B and $1 \mathrm{C}$ show the CAP thresholds before and 4 hours after the administration of $10 \mathrm{mg} / \mathrm{kg} 3 \mathrm{AB}, 20 \mathrm{mg} / \mathrm{kg} \mathrm{NA}$ and $10 \mathrm{mg} / \mathrm{kg}$ $3 \mathrm{ABA}$, respectively ( $n=3$ in each group). Intravenous administration of these compounds did not significantly affect the CAP thresholds (two-way and one-way ANOVA). As shown in

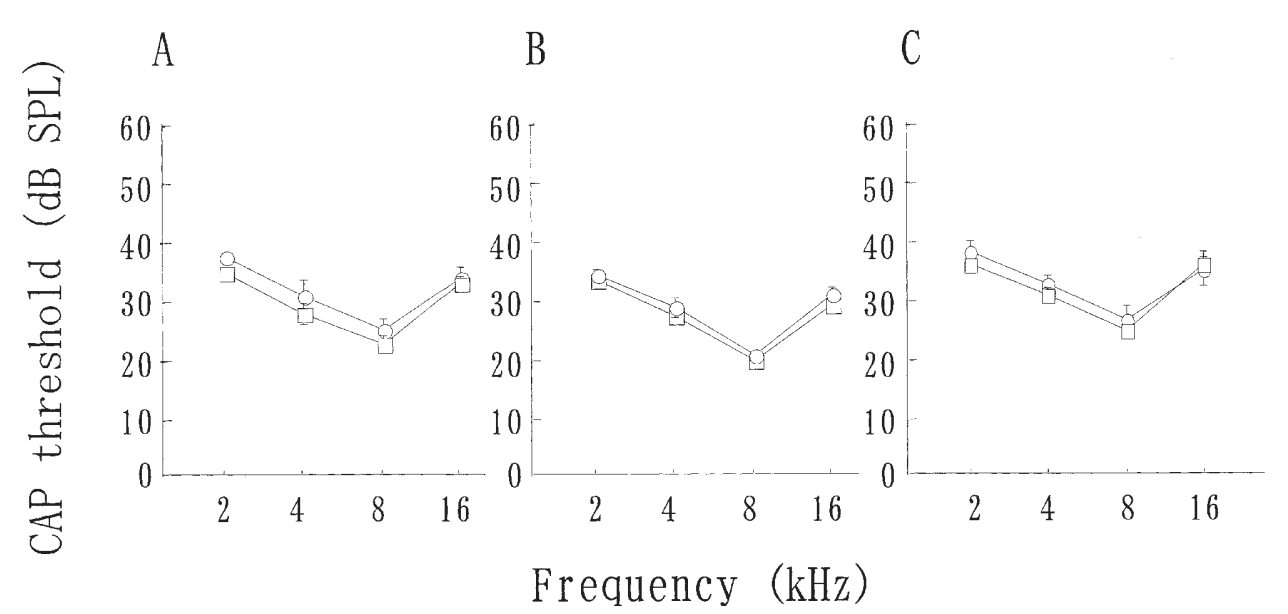

Fig. 1. CAP thresholds before and 4 hours after administration of $10 \mathrm{mg} / \mathrm{kg} 3$-aminobenzamide (A, $n=3), 20 \mathrm{mg} / \mathrm{kg}$ nicotinamide $(\mathrm{B}, n=3)$ or $10 \mathrm{mg} / \mathrm{kg} 3$-aminobenzoic acid $(\mathrm{C}, n=3)$. The pre-and post-administration values are indicated with squares and circles, respectively. The CAP thresholds were not affected significantly by administration of these drugs (two-way and one-way ANOVA, $p>0.05$ ). 


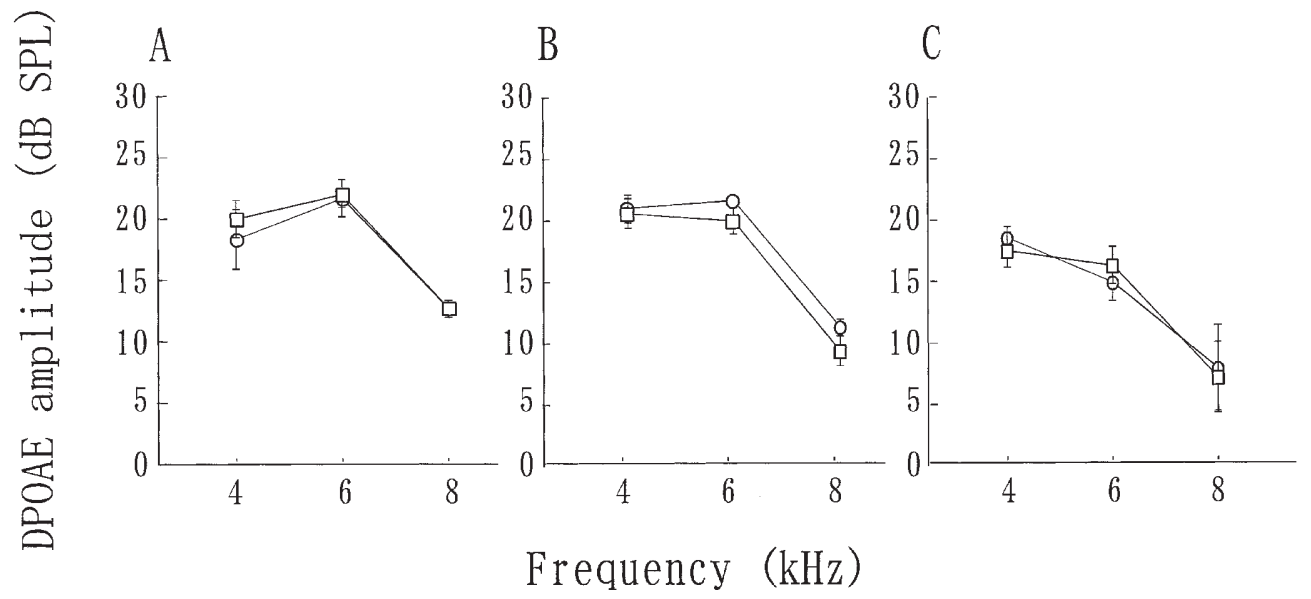

Fig. 2. DPOAE amplitudes before and 4 hours after administration of $10 \mathrm{mg} / \mathrm{kg} 3$ aminobenzamide (A, $n=3), 20 \mathrm{mg} / \mathrm{kg}$ nicotinamide (B, $n=3)$ or $10 \mathrm{mg} / \mathrm{kg} 3$-aminobenzoic acid $(\mathrm{C}, n=3)$. The pre- and post-administration values are indicated with squares and circles, respectively. The DPOAE amplitude was not affected significantly by administration of these drugs (two-way and one-way ANOVA, $p>0.05$ ).

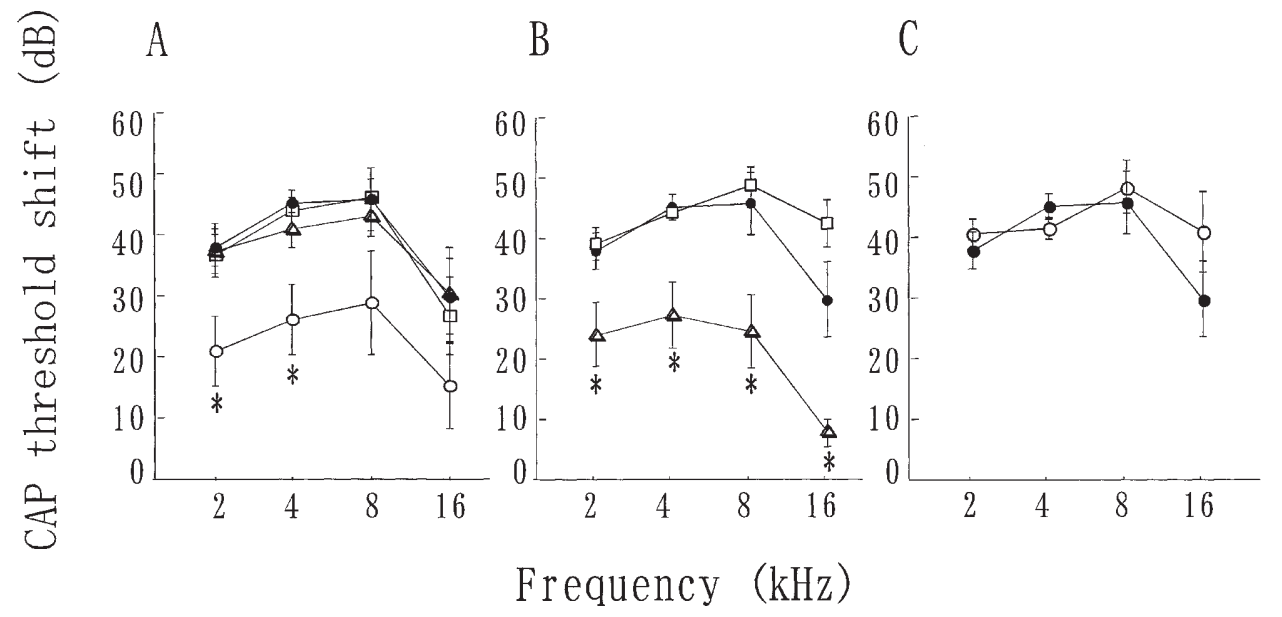

Fig. 3. Threshold shifts in CAP 4 hours after the acoustic overexposure. Closed circles indicate the PSS group. ${ }^{*} p<0.05$ compared to the PSS group with one-way ANOVA followed by Scheffe test.

A: 3-aminobenzamide (3AB) group. Squares, triangles and open circles indicate the 1-, 5and $10-\mathrm{mg} / \mathrm{kg} 3 \mathrm{AB}$ groups, respectively.

B: Nicotinamide (NA) group. Squares and triangles, indicate the 10 - and $20-\mathrm{mg} / \mathrm{kg}$ NA groups, respectively.

C: 3-aminobenzoic acid (3ABA) group. Open circles indicate the 10-mg/kg 3ABA group.

Figs. 2A, B and C, the amplitude of DPOAEs was not significantly affected by these compound, either ( $n=3$ in each group, two-way and one-way ANOVA).

Fig. 3 shows the CAP threshold shifts in 3AB-, NA-and 3ABA-given animals 4 hours after the acoustic overexposure. Although 1 $(n=5)$ or $5(n=5) \mathrm{mg} / \mathrm{kg} 3 \mathrm{AB}$ did not affect the CAP threshold shifts, $10 \quad(n=6) \mathrm{mg} / \mathrm{kg} 3 \mathrm{AB}$ significantly decreased the CAP threshold shifts (two-way ANOVA: $F=7.4, p<0.001$, Scheffe test: $p<0.001$ in the $10 \mathrm{mg} / \mathrm{kg}$ subgroup, $p>$ 

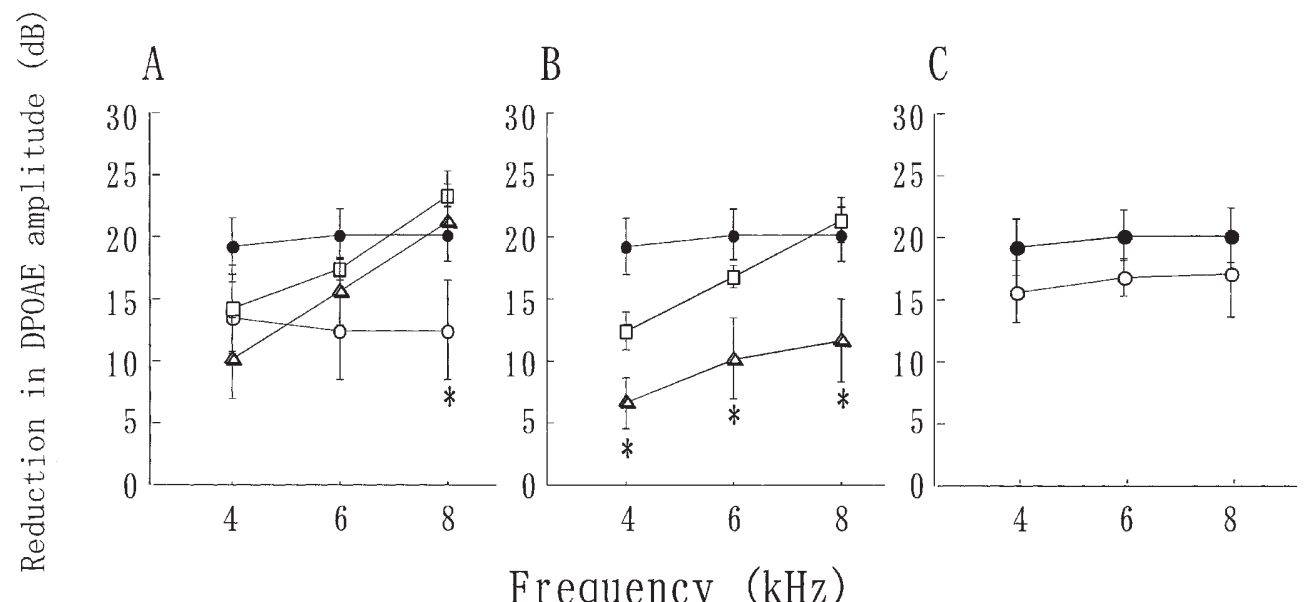

Frequency $(\mathrm{kHz})$

Fig. 4. Amplitude reduction in DPOAEs (dB re pre-exposure level) 4 hours after the acoustic overexposure. Closed circles indicate the PSS group. ${ }^{*} p<0.05$ compared to the PSS group with one-way ANOVA followed by Scheffe test.

A: 3-aminobenzamide (3AB) group. Squares, triangles and open circles indicate the 1-, 5and $10-\mathrm{mg} / \mathrm{kg} 3 \mathrm{AB}$ groups, respectively.

B: Nicotinamide (NA) group. Squares and triangles, indicate the 10 - and $20-\mathrm{mg} / \mathrm{kg} \mathrm{NA}$ groups, respectively.

C: 3 -aminobenzoic acid (3ABA) group. Open circles indicate the $10-\mathrm{mg} / \mathrm{kg} 3 \mathrm{ABA}$ group.

0.05 in the 1 or $5 \mathrm{mg} / \mathrm{kg}$ subgroup, one-way ANOVA and Scheffe test: $p<0.05$ at 2 and 4 $\mathrm{kHz}$ in the $10 \mathrm{mg} / \mathrm{kg}$ subgroup) (Fig. 3A). In addition, although $10(n=5) \mathrm{mg} / \mathrm{kg} \mathrm{NA}$ did not affect the CAP threshold shifts, $20(n=5) \mathrm{mg} / \mathrm{kg}$ NA significantly ameliorated the cochlear dysfunction (two-way ANOVA: $F=33.2, p<$ 0.001 , Scheffe test: $p<0.001$ in the $20 \mathrm{mg} / \mathrm{kg}$ subgroup, $p>0.05$ in the $10 \mathrm{mg} / \mathrm{kg}$ subgroup, one-way ANOVA and Scheffe test: $p<0.05$ at 2 , 4,8 and $16 \mathrm{kHz}$ in the $20 \mathrm{mg} / \mathrm{kg}$ subgroup) (Fig. $3 \mathrm{~B})$. However, $3 \mathrm{ABA}$, an inactive analogue of $3 \mathrm{AB}$, did not affect the CAP threshold shifts at $10 \mathrm{mg} / \mathrm{kg} \quad(n=6$, two-way and one-way ANOVA) (Fig. 3C).

Fig. 4 shows the amplitude reduction in DPOAEs in reference to the pre-exposure level 4 $\mathrm{h}$ after the acoustic overexposure. Although 1 $(n=5)$ or $5(n=5) \mathrm{mg} / \mathrm{kg} 3 \mathrm{AB}$ did not affect the DPOAE amplitudes, $10 \quad(n=6) \mathrm{mg} / \mathrm{kg} 3 \mathrm{AB}$ significantly ameliorated the reduction of the DPOAE amplitude by acoustic overstimulation (two-way ANOVA: $F=3.2, \quad p<0.05$, Scheffe test: $p<0.05$ in the $10 \mathrm{mg} / \mathrm{kg}$ subgroup, $p>0.05$ in the 1 or $5 \mathrm{mg} / \mathrm{kg}$ subgroup, one-way ANOVA and Scheffe test: $p<0.05$ at $8 \mathrm{kHz}$ in the $10 \mathrm{mg} /$ kg subgroup) (Fig. 4A). NA also exhibited the protective effect against acoustic trauma at 20 $\mathrm{mg} / \mathrm{kg}$ (two-way ANOVA: $F=16.7, p<0.001$, Scheffe test: $p<0.001$ in the $20 \mathrm{mg} / \mathrm{kg}$ subgroup, $p>0.05$ in the $10 \mathrm{mg} / \mathrm{kg}$ subgroup, oneway ANOVA and Scheffe test: $p<0.05$ at 4, 6 and $8 \mathrm{kHz}$ in the $20 \mathrm{mg} / \mathrm{kg}$ subgroup) (Fig. 4B). In contrast to the findings observed in the animals treated with PARS inhibitors, there was no statistically significant difference in DPOAEs between the 3ABA-given and the PSS-given groups (two-way and one-way ANOVA) (Fig. 4C).

\section{DISCUSSION}

Since PARS catalyzes the transfer of ADP ribose moieties from NAD to nuclear acceptor molecules, excessive activation of PARS depletes the intracellular concentration of NAD and may lead to cell death (Schraufstatter et al. 1986; Heller et al. 1995; Szabo et al. 1996; Takasawa and Okamoto 2002). Reactive oxygen 
species (Schraufstatter et al. 1986; Hyslop et al. 1988), NO (Heller et al. 1995; Cookson et al. 1998) and peroxynitrite (Szabo et al. 1996; Cookson et al. 1998) have been proposed as powerful triggers of DNA strand breaks and consequent excessive activation of PARS. It has been demonstrated that PARS inhibition ameliorated various CNS (central nervous system) diseases, e.g., Parkinson's disease, brain trauma and ischemia-reperfusion injury (Mikael et al. 1997; Allen et al. 1999; LaPlaca et al. 2001). Recent studies suggest that reactive oxygen species, such as superoxide and hydroxyl radical contribute to acoustic trauma (Seidman et al. 1993; Ohlemiller et al. 1999; Yamasoba et al. 1999; Hara et al. 2000). These findings strongly suggest that activation of PARS by free radicals may also play an important role in this type of injury.

One of the major findings in the present study was the significant protection of cochlear function against acoustic trauma observed in the 3AB- and the NA-given animals. To our knowledge, this finding demonstrated for the first time that PARS plays a deleterious role in acoustic trauma.

Several lines of the evidence suggest that damage to the outer hair cells (OHCs) is the initial effect of acoustic overstimulation (Davis et al. 1989; Hamernik et al. 1989; Boettcher et al. 1992). DPOAEs are supposed to be closely related to an active process in the organ of Corti and are a useful test of OHC function (Whitehead et al. 1992). In the present study, $3 \mathrm{AB}$ and NA significantly increased the DPOAE amplitude 4 hours after noise exposure. Based on this finding, it is highly likely that PARS inhibitors protect OHCs to alleviate CAP threshold shifts after acoustic trauma.

One may argue whether the protective effects of PARS inhibitors demonstrated in the present study are due to its specific effect. In the present study, although $3 \mathrm{AB}$ and NA significantly ameliorated the cochlear dysfunction after noise exposure, 3ABA, an inactive ana- logue of $3 \mathrm{AB}$ that does not inhibit PARS activity (Rankin et al. 1989; Banasik et al. 1992; Thiemermann et al. 1997), did not affect the cochlear function after acoustic trauma. This finding strongly suggests that the protective effects of $3 \mathrm{AB}$ and NA observed in the present study were due to PARS inhibition.

A previous study in our laboratory has demonstrated that the present model of acoustic trauma induces the permanent threshold shift (PTS) (Takahashi et al. 1996). Because we examined cochlear function $4 \mathrm{~h}$ after the acoustic overexposure in the present study, it was not clarified whether PARS inhibitors ameliorated PTS after acoustic injury. However, we confirmed in the mouse model of acoustic injury that $3 \mathrm{AB}$ significantly reduced PTS and loss of OHCs 2 week after acoustic overexposure of 128 $\mathrm{dB}$ SPL for 4 hours (Tabuchi et al. unpublished data).

In conclusion, $3 \mathrm{AB}$ and NA, PARS inhibitors, exerted protective effects against cochlear injury induced by acoustic trauma, although 3ABA did not exhibit such effects. These findings suggest that excessive activation of PARS may play an important role in the generation of acoustic trauma.

\section{References}

Allen, S.M., Serge, P., Vernice, J.-L., Zhao, Q.W., Cynthia, M.S.-R., Mark, E.S., Brian, E.H., Daniel, B.G., Valina, L.D. \& Ted, M.W. (1999) Poly(ADP-ribose) polymerase activation mediates 1-methyl-4-phenyl-1, 2, 3, 6tetrahydropyridine (MPTP)-induced parkinsonism. Proc. Natl. Acad. Sci. USA, 96, 5774 -5779 .

Banasik, M., Komura, H., Shimoyama, M. \& Ueda, K. (1992) Specific inhibitors of poly(ADPribose) synthetase and mono (ADP-ribosyl) transferase. J. Biol. Chem., 267, 1569-1575.

Boettcher, F.A., Spongr, V.P. \& Salvi, R.J. (1992) Physiological and histological changes associated with the reduction in threshold shift during interrupted noise exposure. Hear. Res., 62, 217-236.

Cookson, M.R., Ince, P.G. \& Shaw, P.J. (1998) Per- 
oxynitrite and hydrogen peroxide induced cell death in the NSC34 neuroblastoma $\times$ spinal cord cell line: role of poly(ADP-ribose) polymerase. J. Neurochem., 70, 501-508.

Davis, R.I., Ahroon, W.A. \& Hamernik, R.P. (1989) The relation among hearing loss, sensory cell loss, and tuning characteristics in the chinchilla. Hear. Res., 41, 1-14.

Eliasson, M.J.L., Sampei, K., Mandir, A.S., Hurn, P.D., Traystman, R.J., Bao, J., Pieper, A., Wang, Z.Q., Dawson, T.M., Snyder, S.H. \& Dawson, V.L. (1997) Poly(ADP-ribose) polymerase gene disruption renders mice resistant to cerebral ischemia. Nat. Med., 3, 10891095.

Hamernik, R.P., Patterson, J.H., Turrentine, G.A. \& Ahroon, W.A. (1989) The quantitative relation between sensory cell loss and hearing thresholds. Hear. Res., 38, 199-212.

Hara, A., Serizawa, F., Tabuchi, K., Senarita, M. \& Kusakari, J. (2000) Hydroxyl radical formation in the perilymph of asphyxic guinea pig. Hear. Res., 143, 110-114.

Heller, B., Wang, Z.-Q., Wagner, E.F., Radons, J., Burkle, A., Fehsel, K., Burkart, V. \& Kolb, H. (1995) Inactivation of the poly(ADP-ribose) polymerase gene affects oxygen radical and nitric oxide toxicity in islet cells. J. Biol. Chem., 270, 11176-11180.

Hyslop, P.A., Hinshaw, D.B., Halsey, W.A., Schraufstatter, I.U., Sauerheber, R.D., Spragg, R.G., Jackson, J.H. \& Cochrane, C.G. (1988) Mechanisms of oxidant-mediated cell injury. J. Biol. Chem., 263, 1665-1675.

LaPlaca, M.C., Zhang, J., Raghupathi, R., Li, J.-H., Smith, F., Bareyre, F.M., Snyder, S.H., Graham, D.I. \& McIntosh, T.K. (2001) Pharmacologic inhibition of poly(ADP-ribose) polymerase is neuroprotective following traumatic brain injury in rats. J. Neurotrauma., 18, 369-376.

Ohlemiller, K.K., Wright, J.S. \& Dugan, L.L. (1999) Early elevation of cochlear reactive oxygen species following noise exposure. Audiol. Neurootol., 4, 229-236.

Okubo, H., Akizuki, H., Kawashima, N., Morita, Y., Ito, Z., Ase, Y., Nakata, H. \& Kusakari, J. (1995) Distortion-product otoacoustic emissions in experimentally induced hydropic ears. Acta Otolaryngol. (Stockh) Suppl., 519, 97-101.

Rankin, P.W., Jacobson, E.L., Benjamin, R.C., Moss, J. \& Jacobson, M.K. (1989) Quantitative studies of inhibitors of ADP-ribosylation in vitro and in vivo. J. Biol. Chem., 264, 43124317.

Schraufstatter, I.U., Hyslop, P.A., Hinshaw, D.B., Spragg, R.G., Sklar, L.A. \& Cochrane, C.G. (1986) Hydrogen peroxide-induced injury of cells and its prevention by inhibitors of poly(ADP-ribose) polymerase. Proc. Natl. Acad. Sci. USA, 83, 4908-4912.

Seidman, M.D., Shivapuja, B.G. \& Quirk, W.S. (1993) The protective effects of allopurinol and superoxide dismutase on noise-induced cochlear damage. Otolaryngol. Head Neck Surg., 109, 1052-1056.

Szabo, C., Zingarelli, B., O’Connor, M. \& Salzman, A. (1996) DNA strand breakage, activation of poly(ADP-ribose) synthetase, and cellular energy depletion are involved in the cytotoxicity in macrophages and smooth muscle cells exposed to peroxynitrite. Proc. Natl. Acad. Sci. USA, 93, 1753-1758.

Tabuchi, K., Okubo, H., Fujihira, K., Tsuji, S., Hara, A. \& Kusakari, J. (2001a) Protection of outer hair cells from reperfusion injury by an iron chelator and nitric oxide synthase inhibitor. Neurosci. Lett., 307, 29-32.

Tabuchi, K., Tsuji, S., Ito, Z., Hara, A. \& Kusakari, J. (2001b) Does xanthine oxidase contribute to the hydroxyl radical generation in ischemia and reperfusion of the cochlea? Hear. Res., 153, 1-6.

Takahashi, K., Kusakari, J., Kimura, S., Wada, T. \& Hara, A. (1996) The effect of methylprednisolone on acoustic trauma. Acta Otolaryngol. (Stockh), 116, 209-212.

Takasawa, S. \& Okamoto, H. (2002) Pancreatic $\beta$-cell death, regeneration and insulin secretion: Roles of Poly(ADP-ribose) polymerase and cyclic ADP-ribose. Int. J. Exp. Diabetes Res., 3, 79-96.

Thiemermann, C., Bowes, J., Myint, F.P. \& Vane, J.R. (1997) Inhibition of the activity of poly(ADP ribose) synthetase reduces ischemiareperfusion injury in the heart and skeletal muscle. Proc. Natl. Acad. Sci. USA, 94, 679683.

Whitehead, M.L., Lonsbury-Martin, B.L. \& Martin, G.K. (1992) Evidence for two discrete sources of 2f1-f2 distortion-product otoacoustic emission in rabbit: II. Differential dependence on stimulus parameters. J. Acoust. Soc. Am., 91, 1587-607. 
Yamasoba, T., Schacht, J., Shoji, F. \& Miller, J.M. (1999) Attenuation of cochlear damage from noise trauma by an iron chelator, a free radical scavenger and glial cell line-derived neurotrophic factor in vivo. Brain Res., 815, 317325. 